\title{
PHYTOCHEMICAL SCREENING AND ANTIMICROBIAL ACTIVITY OF AZADIRACHTA INDICA AND PLECTRANTHUS AMBOINICUS EXTRACT
}

\author{
GEJALAKSHMI S. ", R. SENTHILRAJ, TANISHA B. A., SRUTHI S., THARUN KUMAR M., POOJA G. \\ Faculty of Pharmacy, Dr. M. G. R. Educational and Research Institute, Chennai-77 \\ Email: gejampharm@gmail.com
}

Received: 12 Sep 2019, Revised and Accepted: 25 Nov 2019

\section{ABSTRACT}

Objective: In the present research, a clear systematic investigation of phytochemical screening and antibacterial activity of herbal plants such as Azadirachta indica and Plectranthus amboinicus has been carried out.

Methods: The aqueous and alcoholic extract was prepared in soxhlet apparatus and phytochemical analysis of extracts was performed and analysed. The in vitro antimicrobial activity was performed by cup plate method. These extracts were studied under agar diffusion method against three bacterial species such as Bacillussubtills, Staphylococcus aureus, and Escherichia coli at $5 \mu \mathrm{g}, 50 \mu \mathrm{g}$ and $250 \mu \mathrm{g}$ concentration.

Results: The combine extract showed a predominant activity against these bacteria, which confirmed antimicrobial activity in AEAI and AEPA

Conclusion: The results obtained in this study clearly indicate that AEAI and AEPA has a significant potential to use as an antimicrobial agent

Keywords: Herbal plant, Antimicrobial activity

(C) 2020 The Authors. Published by Innovare Academic Sciences Pvt Ltd. This is an open-access article under the CC BY license (http://creativecommons.org/licenses/by/4.0/) DOI: http://dx.doi.org/10.22159/ijcpr.2020v12i1.36822. Journal homepage: https://innovareacademics.in/journals/index.php/ijcpr

\section{INTRODUCTION}

Infectious diseases are a significant cause of morbidity and mortality worldwide, accounting for approximately $50 \%$ of all deaths in the world especially in developing countries [1]. Despite the progress made in understanding the biology and control of pathogenic microorganisms sporadic incidents of epidemics have emerged due to drug-resistant microbes posing an enormous threat to public health. The alarming increase in the rate of infectious diseases with antibiotic-resistant microorganisms and side effects of some synthetic antibiotics has led to increasing interest towards medicinal plants as a natural alternate to synthetic drugs [2]. Although most antibiotics are still active, the rapid progression of resistance suggests that many of these drugs may not be effective for much longer. Research and development of new therapies for treating bacterial infections are of immediate need.

Azadirachta indica A. Juss., Meliaceae, commonly known as neem, originated from South and Southeast Asia, is also found in tropical and subtropical areas of Africa, America and Australia [3]. In India, it is commonly known as 'Divine Tree', 'Life-giving tree', 'Nature's Drugstore', 'Village Pharmacy' and 'Panacea for all diseases' [4]. Products made from neem trees have been used in India for over two millennia for their medicinal properties [5]. It is considered a major component in siddha medicine and Ayurveda and Unani medicine and is particularly prescribed for skin diseases [6]. It has a various biological activity such as anti-inflammatory, antiarthitic, antipyretic, hypoglycaemic, antigastric ulcer, anti-tumour, immunomodulatory etc. Neem oil and the bark and leaf extracts have been therapeutically used as folk medicine to control leprosy, intestinal helminthiasis, respiratory disorders, and constipation and also as a general health promoter. Its use for the treatment of rheumatism, chronic syphilitic sores and indolent ulcer has also been evident [7].

Plectranthus amboinicus (Lour) Spreng belongs to family Lamiaceae and known as country borage in English. It is large succulent aromatic perennial herb, shrubby below, hispidly villous or tomentose. It is found throughout India, Sri Lanka and Moluccas. The leaves of the plant are bitter, acrid and were being widely used traditionally for various purposes [8]. The extract of this plant has a various therapeutic activity such as anti-inflammatory, chronic cough, urinary disease. It also contains various activities such as anti-microbial, cytotoxic and anti-oxidant. It can be used as an herbal nutrition supplement and can be considered as a multivitamin supplementary agent for vitamin deficiency patients [9]. Itis used as a remedy for burns and bites, internally as carminative and antiasthma, and applied externally as insect bite repellent [10]. This research article shows the result of the antimicrobial activity from the aqueous extract of Azadirachta indica and Plectranthus amboinicus.

\section{MATERIALS AND METHODS}

\section{Plant material}

Healthy leaves of as Azadirachta indica and Plectranthus amboinicus were collected from south Tamilnadu Tirunelveli district and used for the preparation of aqueous and different solvent extracts. The plant and variety was identified by the taxonomists of the Department of plant anatomy research center Tambaram Chennai.

\section{Test pathogens}

Authentic cultures of human pathogenic bacteria viz., E. coli, $B$. subtilis, and Staph. aureus obtained from Microbial Type Culture Collection Chennai India-which served as test bacteria. All the bacterial cultures were maintained in nutrient agar slants with periodic sub-culture.

\section{Preparation of extracts}

A Soxhlet extractor is a piece of laboratory apparatus invented in 1879 by Franz von Soxhlet. It was originally designed for the extraction of a lipid from a solid material. The leaf of Azadirachta indica and Plectranthus amboinicus placed inside a thimble made from thick filter paper, which is loaded into the main chamber of the Soxhlet extractor. The Soxhlet extractor is placed onto a flask containing the extraction solvent methanol. The Soxhlet is then equipped with a condenser. Then the solvent is heated to reflux. The solvent vapour travels up a distillation arm, and floods into the chamber housing the thimble of solid. The condenser will ensures that any solvent vapour cools, and drips back down into the chamber housing the solid material. The chamber containing the solid material slowly fills with a warm solvent. Some of the compounds 
dissolved in the warm solvent. When the Soxhlet chamber is almost full, then chamber automatically emptied by a siphon side arm, with the solvent running back down to the distillation flask. Then the cycle was allowed to repeat many times, over hours or days. During each cycle, a portion of the non-volatile compound was dissolved in the solvent. After many cycles the crude extract is concentrated in the distillation. After extraction, the solvent is removed, typically by means of a rotary evaporator, yielding the extracted compound. The non-soluble portion of the extracted solid remains in the thimble, and discarded. Extract was continued for evaluation of antimicrobial activity.

\section{Antimicrobial}

An antibiotic is chemical compound which inhibits the growth of survival of one or more species of microorganisms. The drug is considered as bacteriostatic or fungistatic activity when it inhibits or kill the growth microorganisms respectively. Antibacterial activity of aqueous extract and solvent extracts was determined by agar cup diffusion [11] and cup plate method [12].

\section{Method and procedure}

\section{Agar cup diffusion assay}

Cups were made in plates containing $20 \mathrm{ml}$ of nutrient agar media using sterile cork borer $(6 \mathrm{~mm})$ and inoculum containing $10^{6}$ $\mathrm{CFU} / \mathrm{ml}$ of bacteria were spread uniformly over the solid media with a sterile swab moistened with the bacterial suspension. The dried aqueous and solvent extracts were reconstituted respectively in sterile distilled water and methanol to a concentration of 100 $\mathrm{mg} / \mathrm{ml}$. Aqueous and solvent extracts of $100 \mu \mathrm{l}$ were placed in the cups made in the inoculated plates. Also, $100 \mu \mathrm{l}$ of sterilized distilled water and methanol were placed in the cups separately which served as negative control and $100 \mu \mathrm{l}$ of antibiotic-containing $100 \mu \mathrm{g}$ streptomycin (streptomycin sulfate IP; $1 \mathrm{mg} / \mathrm{ml}$ ) served as positive control. The plates were incubated for $24 \mathrm{~h}$ at $37^{\circ} \mathrm{C}$ and zone of inhibition if any around the cups were measured in $\mathrm{mm}$. For each treatment, four replicates were maintained and repeated twice.

\section{Cup plate assay}

The medium was prepared by dissolving the dehydrated medium in purified water of $100 \mathrm{ml}$, in $250 \mathrm{ml}$ conical flask. The conical flask were closed with cotton plugs and were sterilized by autoclaving at $121{ }^{\circ} \mathrm{c}$ for $15 \mathrm{~min}$. The contents of the conical flask were poured aseptically into sterile petri dishes are allowed to solidify. These sterilized media were used to subculture the bacterial culture. Each petri dishes was filled with a depth of 4 to $5 \mathrm{~mm}$ with a nutrient agar medium that was previously solidified. The petri dishes were specially selected with a flat bottom and were placed on level surface to ensure the layer of medium is in uniform thickness. Small sterile borer of uniform size was placed approximately at $10 \mathrm{~cm}$ height having an internal diameter of 6 to $8 \mathrm{~mm}$. The petri dishes were incubated at $37^{\circ} \mathrm{C}$ for $18 \mathrm{~h}$. Diameter of the zone of inhibition was measured and the average diameter for each sample was calculated. The diameter obtained by the test sample was compared with that produced by standard ofloxacin.

\section{RESULTS}

\section{Extraction of plant material}

The physical appearance and \%yield is given in table 1 .

\section{Preliminary phytochemical screening}

Preliminary Phytochemical screening was evaluated and the results are given in table 2 .

\section{Antimicrobial activity of AEPA and AEAI}

Antimicrobial activity of AEPA and AEAI was determined by cup plate method.

Both AEPA and AEAI exhibited significant antibacterial activity against all the microorganisms studied. The study also revealed that AEPA has more antibacterial activity than AEAI at the microbiology laboratory conditions of test although both the extracts exhibited less activity than ofloxacin and the results are given in table 3 and fig. 1 and 2 .

Table 1: Properties of extract

\begin{tabular}{lll}
\hline Name of aqueous extract & Physical appearance & \%yield \\
\hline Plectranthus ambonicus & Brownish green & $\mathbf{7 2}$ \\
Azadirachta indica & Brownish-yellow & $\mathbf{7 0}$ \\
\hline
\end{tabular}

Table 2: Preliminary phytochemical screening of AEPA and AEAI

\begin{tabular}{|c|c|c|c|}
\hline Phytochemicals & Test/reagent & AEPA & AEAI \\
\hline \multirow[t]{4}{*}{ Alkaloids } & Dragendorff's test & + & + \\
\hline & Mayer's test & + & + \\
\hline & Hager's test & + & + \\
\hline & Wagner's test & + & + \\
\hline \multirow[t]{3}{*}{ Carbohydrates } & Molisch's test & + & + \\
\hline & Fehling's test & + & + \\
\hline & Benedict's test & + & + \\
\hline \multirow[t]{2}{*}{ Glycosides } & Legal's test & + & + \\
\hline & Keller-Killiani test & + & + \\
\hline \multirow[t]{2}{*}{ Steroids } & Libermann-Burchard test & + & - \\
\hline & Salkowski test & + & - \\
\hline Flavonoids & Shinoda's test & + & + \\
\hline Saponins & foam test & + & + \\
\hline \multirow[t]{2}{*}{ Fixed oils and fats } & Spot test & - & - \\
\hline & Saponification test & - & - \\
\hline \multirow[t]{3}{*}{ Tannins and phenolic compounds } & Lead acetate test & + & + \\
\hline & Ferric chloride test & + & + \\
\hline & Potassium dichromate test & + & + \\
\hline \multirow[t]{2}{*}{ Protein and amino acids } & Ninhydrin test & + & - \\
\hline & Million's test & + & - \\
\hline Triterpenes & Sulphuric acid test & + & + \\
\hline
\end{tabular}

+present,-absent 
Table 3: Zone of inhibition (mm) of different bacterial agents at various concentrations of the test extract and the standard ofloxacin

\begin{tabular}{lllll}
\hline Test sample & Concentration $(\boldsymbol{\mu g} / \mathbf{m l})$ & \multicolumn{2}{l}{ Zone of inhibition $(\mathbf{m m})$ mean \pm SEM } & S. aureus \\
\cline { 3 - 5 } & & B. subtilis & $23 \pm 1.4$ & E. coli \\
\hline Ofloxacin & 5 & $21.6 \pm 1.2$ & - & - \\
AEPA and & 50 & $-6 \pm 0.1$ & $6 \pm 0.1$ & $6 \pm 0.1$ \\
AEAI & 100 & $10 \pm 0.5$ & $13.4 \pm 0.6$ & $14 \pm 0.2$ \\
& 250 & - & - & - \\
\hline
\end{tabular}
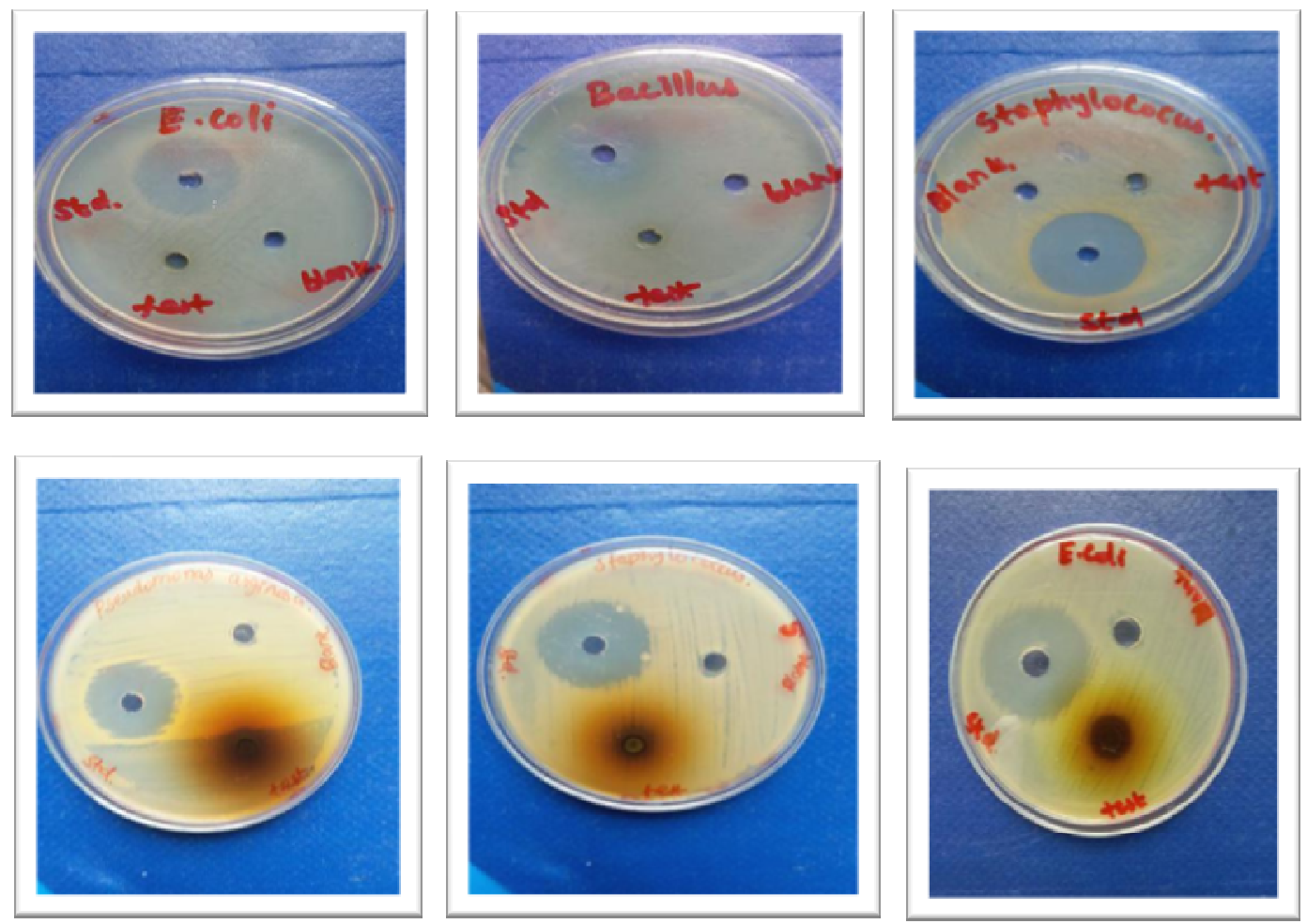

Fig. 1: The study also revealed that AEPA has more antibacterial activity than AEAI at the microbiology laboratory conditions of test although both the extracts exhibited less activity than ofloxacin and the results are given

\section{DISCUSSION}

Fresh Leaves of Azadirachta indica and Plectranthus amboinicus were selected based on their uses in the treatment of various types of disease. Azadirachta indica is traditionally used for the anthelmintic, anti-fungal, anti-diabetic, antiviral, contraceptive and sedative [13]. Therapeutically, the leaf extract is used for its antimicrobial activity against dental pathogens [14] Plectranthus amboinicus is used antifungal, anti leptospiral, rheumatoid arthritis and nephroprotective activity [15].

Natural products are both a fundamental source of new chemical diversity and an integral part of today's pharmaceutical compendium. Many currently available antibacterial agents have undesirable toxicity and these drugs have led to the rapid development of drug-resistant strains. About $75-80 \%$ of the world's population in developing countries mainly depends on herbal medicine for primary health care because of better compatibility with the human body and less side effects [16]

Preliminary Phytochemical investigations were carried out in order to characterize the collected plant samples. The results were compared with that of published data. Preliminary Phytochemical studies of leaves of Azadirachta indica and Plectranthus amboinicus revealed the presence of alkaloids, carbohydrates, glycosides, Flavonoids, saponins, tannins, and triterpenes. The phytochemical constituents observed are similar to the reported data $[17,18]$.

The study was extended to evaluate the antimicrobial activity of AEAI and AEPA since they might protect the system against infections by its antimicrobial activity or by strengthening body defence mechanism or by both. Having confirmed the immunomodulatory activity of AEEA and AETA the antimicrobial activities of the above extracts against gram+ve (Bacillus subtilis, Staphylococcusaureus) and gram-ve (Escherichia coli) bacteria were carried out. Combined extract of AEAI and AEPA exhibited antibacterial activity against Bacillus subtilis, Staphylococcus aureus, and Escherichia coli at $250 \mu \mathrm{g} / \mathrm{ml}$ [19]. The antibacterial activity was more pronounced with gram+ve bacteria than a gram-ve bacteria which are evident from table 3 . This may be due to the easy accessibility to cell walls of Gram+ve bacteria by the extracts. The study reveals that Azadirachta indica and Plectranthus amboinicus have more antibacterial activity at the microbiology laboratory conditions of test although both the extracts exhibited less activity than ofloxacin. So the use of AEAI and AEPA with known phytochemical and antimicrobial properties is able to great significance in therapeutic treatments.

\section{CONCLUSION}

In conclusion, the present study a potent antibacterial activity against three pathogenic bacteria by Azadirachta indica and Plectranthus amboinicus, extracts especially methanol extract and good scavenging ability of all the extracts leads to scientific validation of the plant. A natural substance which is a part of daily diet nutritional supplement with antimicrobial property constitutes a new source of herbal drug. Further exploration on the isolated element on antimicrobial and antioxidant activity may lead to chemical entities for clinical use. The phytochemical analysis result impacts on therapeutic value. 


\section{ACKNOWLEDGMENT}

The first author Gejalakshmi is thankful to our management of Dr. M. G. R. Educational and Research Institute Chennai to carry out this research in efficacy manner. We also thank our Department Taxonomists for identifying the plant species used in the study.

\section{FUNDING}

\section{Nil}

\section{AUTHORS CONTRIBUTIONS}

All the authors have contributed equally.

\section{CONFLICTS OF INTERESTS}

The authors declared that they have no conflicts of interest

\section{REFERENCES}

1. World Health Report. Geneva, Switzerland; 2003. p. 1-150

2. D Ragunath. Emerging antibiotic resistance in bacteria with special reference. Indian J Biosci 2008;33:593-603.

3. Venugopalan Santhosh Kumar, Visweswaran Navaratnam, Neem (Azadirachta indica). Prehistory to contemporary medicinal uses to humankind; 2013. p. 505-14.

4. IRamadass N, Subramanian N. Study of phytochemical screening of neem (Azadirachta indica). Int J Zool Studies 2018;3:209-12.

5. Porter, Anna Horsbrugh. Neem: India's tree of life, BBC; 2006.

6. Jairajpuri S, Zillur Rahman, M Shamim SL. Neem in unani medicine. Neem in unani medicine. India New Delhi; 1993.

7. Agrawal DP. Medicinal properties of Neem: New Findings; 1992.

8. Roshan Patel, Naveen Mahobia, Naheed Waseem, Nitin Upwar. Phyto-physicochemical investigation of leaves of plectranthus amboinicus. Pharmacogn J 2010;2:25-7.
9. Overlay Panel Seham S, El-hawary Rabie H, El-sofany Azza R, Abdel Monem Rehab S, Ashour. Phytochemical screening, DNA fingerprinting, and nutritional value of plectranthus amboinicus (Lour.). Spreng 2012;4:20-30-32.

10. Whistler WA. Tropical ornament SL: Timber Press Portland, Oregon USA; 2000.

11. Perez C, Pauli M, Bazerqu. An antibiotic assay by the well agar method. Acta Biol Med Exp 1990;15:13-5.

12. Shukla, Nayan R, Bhalodia VJ. Antibacterial and antifungal activities from leaf extracts of cassia fistula l.: an ethnomedicinal plant. J Adv Pharm Technol Res 2011;2:104-9.

13. Choudhary, Vijay. Description and medicinal uses of azadirachta Indica (Neem); 2019.

14. Khan, SS Rao, S Darsipudi, SG Divya, H Amaranad. Phytochemical studies and screening of leaves extracts of azadirachta indica for its anti-microbial activity against dental pathogens. IJCP 2010;2:23-6.

15. C Koti, Aparna Gore, AHM Thippeswamy, AHM Viswanatha Swamy, Rucha Kulkarni. Alcoholic leaf extract of plectranthus amboinicus regulates carbohydrate metabolism in alloxaninduced diabetic rats. Indian J Pharmacol 2011;6:32-6.

16. B Jayalakshmia, KA Raveeshab, M Muralic, KN Amruthesh. Phytochemical, antibacterial and antioxidant studies on leaf extracts of piper betle l. Int J Pharm Pharm Sci 2015;7:10.

17. Panel Zainab, Saif Saleh, Al-Hashemi Mohammad. Biological activities of different neem leaf crude extracts used locally in Ayurvedic medicine. Pacific Sci Rev: Nat Sci Eng 2016;18:128-31.

18. https://www.webmd.com/vitamins/ai/ingredientmono577/neem. [Last accessed on 10 Aug 2019]

19. Sharada L Deore, Khadabadi Lalita, Bhagure SS, DS Ghorpade. In vitro antimicrobial and antioxidant studies on Enicostemma axillare (Lam) Raynal leaves. Nat Prod Radiance 2008;7:409-12. 